\title{
Online interactivity: best practice based on two case studies
}

\author{
Tom Boyle and John Cook \\ University of North London \\ email: t.boyle@unl.ac.uk
}

The purpose of this paper is to identify and explore best practice in the effective support of online interactivity. Five key issues related to best practice are delineated, based on the experience derived from two case studies. The first case study involved online, collaborative work carried out by twenty-six conversion M.Sc. students following a module on 'Interactive Multimedia Systems'. The online group work was structured around the production of essay-style critiques and the development of prototype multimedia resources. The discussions were structured using the bulletin board facility in WebCT. The second study involved sixty-four second-year undergraduate students following a module on 'Communication via Multimedia'. These students were involved in assessed online discussion groups that aimed to foster a community in enquiry and provide an opportunity for vicarious learning. The assessed discussion groups were based on Netscape Collabra. A comparison of the experience of these two case studies led to the identification of a set of five key issues relating to best practice in the effective support of online interactivity. The first four issues concern the design and implementation of the online learning experiences. The fifth issue involves reflection and improvement on the interventions made.

\section{Introduction}

This paper compares the experiences of two studies in the use of network supported collaborative learning. These studies aimed to enhance the learning experience of traditional campus-based students. The courses used a hybrid of face-to-face contact and collaborative work mediated through electronic networks. The aim of the studies was to provide an enhanced educational experience to these traditional student cohorts.

The paper presents a comparison of the experience of these two studies. Based on this comparison a set of key factors is distilled that seem to influence strongly the nature and 
success of networked learning. The first two sections of the paper, following the introduction, describe the purpose and implementation of the two studies. The first study represents an intervention in a postgraduate course. The second study involved secondyear undergraduate students. The evaluation of these two studies, based on a mixture of observation, questionnaire and focus groups, is then presented. Certain key factors that influenced the nature and success of the studies are distilled. The paper proposes that consideration of these key factors is important for the successful implementation of networked learning, especially in a campus-based setting.

\section{First case study: enhancing group projects}

The focus of this project was to provide integrated computer support to students of educational multimedia design. The students were following a unit on Interactive Multimedia Systems as part of an M.Sc. conversion course in computing. A significant objective of the project was to bring together traditional strengths of the Web and multimedia to provide an enhanced learning environment that would instantiate many of the principles being taught on the course. The project involved identifying the main layers of support required (Collis, 1997), providing computer-based assistance at each of these layers, and integrating this support into major class activities.

The Interactive Multimedia Systems module ran for one semester with a lecture each week followed by a practical session of three hours. The theory covered in the lectures was supported by the use of the textbook, Design for Multimedia Learning (Boyle, 1997). For the first five weeks the practicals were used to introduce multimedia-authoring skills. From about Week 5 to the end of the module (twelve weeks), the students in the courseware for the unit deployed these skills.

The assignment for the unit was conducted as a group-based collaborative project. The students were divided into groups of four or five, and each group was given a mini-project to conduct over approximately seven weeks. In previous years the project had consisted of designing and creating a multimedia prototype. This work was assessed through demonstrations and interviews with the students at the end of the semester. Since it was very difficult to keep track of the individual contributions to the group work the mark consisted of a group mark and a larger individual mark (usually around 70 per cent). The group work thus was always structured to ensure significant, clearly identifiable individual components.

In the target semester two main changes were made to provide improved support for student learning. The main change at the courseware layer was the provision of a multimedia Web site to complement the course textbook. The purpose of the DFML (Design for Multimedia Learning) Web site was not to replace the textbook or place course notes on the Web. The aim was to provide a multimedia complement to the theoretical material covered in the textbook (Figure 1). The book remains the main medium for the detailed exposition of underlying concepts and theoretical structures. The site seeks to provide experiences and activities that cannot be provided in a book, including multimedia demonstrations, interactive examples and links to other Web sites. This enhanced courseware should enable the learner to engage in richer learning experiences than can be provided by the book alone (or indeed the Web site alone). 


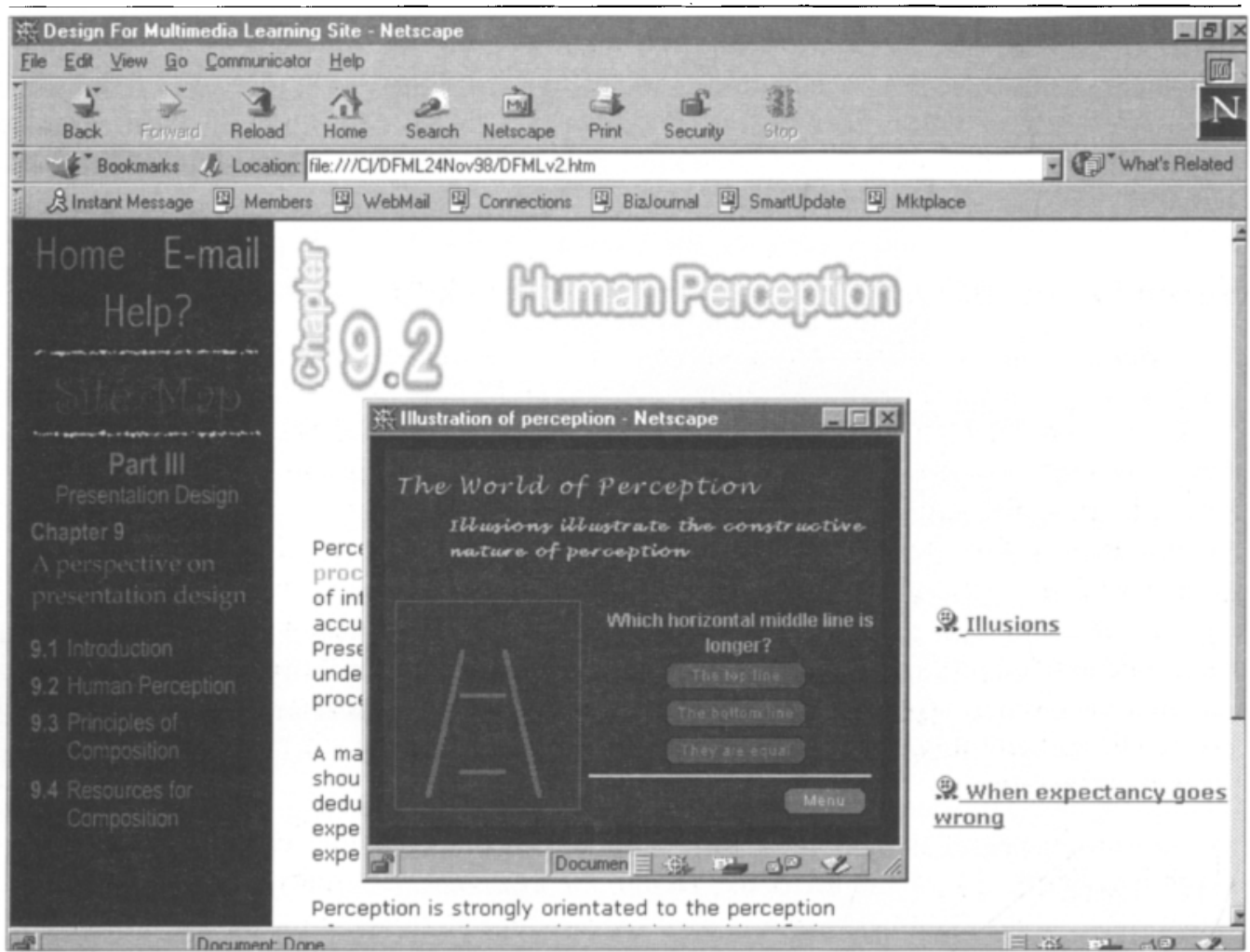

Figure 1: The DFML Web site.

The DFML site was designed to elicit the active engagement of students. This supported changes made in how the assessed group project in the module was conducted. In the target semester the DFML site was introduced into the course and the coursework component for the module was changed. The students were given access to a new Web site. The home page for this site contained two main links. The first link was to the DFML Web site; the second link was to the bulletin board facility in WebCT. The students were organized into small groups. Each group was set up as a separate discussion group in the WebCT bulletin board facility. The students were asked to work co-operatively to complete two subtasks, to produce:

- online critiques of the chapters in the book/site and to suggest enhancements and improvements: The students were encouraged to identify and reference Web sites that might later be incorporated as extra links in the main site;

- a small multimedia resource to illustrate a topic in the book/site which they could choose.

The students were informed at the beginning of the concept of the site being updated by its users. They were told that good features produced by the groups could be incorporated in the site for use by future students. The students were asked to work collaboratively, using the group bulletin board, to exchange ideas and organize the group's work. The proposition that one mark would be given to each group (with the possibility of individual 
moderation of marks) was presented to the class. They agreed to this approach. The first part of the coursework involved the development of group plans; the second part entailed the chapter critiques. Both the initial group plans and the chapter critiques were submitted electronically though WebCT. The final part of the coursework involved the creation and demonstration of the multimedia resource.

\section{Second case study: encouraging discussion skills}

The second study involved sixty-four second-year undergraduate students who were studying on a module called 'Communicating via Multimedia'. The students on this module were given access to various Web resources, such as the DFML Web site described above, as well as a conferencing facility. Participants in the module were involved in assessed online discussion groups that aimed to foster a community of enquiry and provide an opportunity for vicarious learning. A community of enquiry (Lipman, 1991) is a teacher-guided approach to reflective education that places an emphasis on social interaction and co-operative learning; it also involves critical reasoning and judgement about open-ended problems, i.e. problems and subject areas where there is no single correct answer to a given problem (Cook, 2000). The starting assumption for vicarious learning (McKendree, Stenning, Mayes, Lee, and Cox, 1998) is that much real learning occurs through observation of other learners engaged in active dialogues.

On the module students had to complete two assessment tasks, each carrying equal weighting. There was no exam. The focus of this second case study was assessment 1 , which involved groups of students co-operating to devise and apply criteria for Web site evaluation and a subsequent online debate about this evaluation task. The assessment task was an open-ended one; i.e. there were many possible sets of criteria that could have been selected by the students to evaluate a Web site. We were particularly keen to design the online interactions with students on the module in such a way that would promote critical debate about the assessment task.

A live debate relating to the assignment would not, in the authors' view, have taken place if students were not motivated in some way. Consequently, the marking scheme for the assignment, out of a total of fifty, included thirty marks for group work and twenty marks for individual work. The individual marks for the online debate were ten marks for demonstrating an ability to answer questions and ten marks for taking a lead in the discussion and showing an awareness of the issues.

Students were asked to make at least three postings to the online debate. The central focus in this study was thus the development of discussion and debating skills, and the assessment tasks reflected this target. By contrast, in the first study the online discussion was a means to an end - producing online group critiques and multimedia resources.

\section{Evaluation}

\section{Study I}

The evaluation entailed a mixture of quantitative and qualitative methods. This mixture of methods provides summary numerical data supported by richer insights based on discussion (Atkins, 1993; England and Finney, 1999). A questionnaire was used to gather 
information on the students' assessment of the DFML site, and the use of electronic group work using WebCT. This questionnaire was followed by focus group discussions.

The questionnaire results can be divided into three parts. These parts relate to the evaluation of respectively: the use of WebCT, the main DFML site, and the multimedia resources accessed through the site. This paper focuses on the results for the use of group online conferencing. The evaluation of the DFML site and the multimedia resources it contained are reported in Boyle (1999) and Boyle and Payne (1999).

The questions used a scale from one to four, where one indicates 'very poor' and four indicates 'very good'. The students found the group bulletin board facility in WebCT very easy to use. The overall median score was 3.5 out of $4-50$ per cent of the students rated the use of the group conferencing in WebCT as 'very good'. They also found it very easy to move between the WebCT environment and the DFML site (median 4). The focus group discussions confirmed that the group conferencing was very popular. The part-time students especially appreciated the flexibility of structured electronic communication. It helped them to keep in touch throughout the week with the full-time members of the group.

From the tutor's point of view the use of WebCT was a very useful innovation. The tutor was entered as a member of each group. He could thus keep track of the activities within the groups. The students used the facilities to plan and co-ordinate group activities, send drafts to each other, and comment on these drafts. From the tutor's point of view the ability to 'see' the activities within the group was a marked improvement on the previous method of group working. The logging facilities in WebCT also made it easy to produce summary reports on the students' activities. These activities included the number of communications sent and read in the group bulletin boards. This knowledge provided the basis for greater confidence in allocating assessment marks to the groups. Group members could also be asked about differences in the activities of individuals revealed by the online monitoring, and this information often proved informative in ascertaining the reasons for variations in overt activity. As a consequence, for the first time in the history of the module the lecturer had the confidence to award a genuine single-group mark for the collaborative work. In cases where there was some doubt, face-to-face discussions were held with the group to clarify the issue of individuals' contributions. These discussions were also used to confirm that the students continued to be satisfied with the concept that an overall group mark be awarded.

\section{Study 2}

The evaluation of the module made use of an anonymous questionnaire. Sixty-one out of sixty-four students taking the module completed the questionnaire. As with study 1 , the students were asked to respond to each question with a score between one and four, where one was 'very poor' and four was 'very good', or some equivalent wording appropriate to the question. The questionnaire left a space for additional comments after each question.

For the ten-day period of the assignment there were around 400 postings in the online debate. The quality of dialogue varied, of course, but student feedback via the module evaluation was generally good. Most of the students were reasonably satisfied with the Web pages and conferencing used on the module. Table 1 shows the total student responses to eleven questions, by score category (one to four) and expressed as a percentage of the 
total number of question responses (the total being $11 \times 61=671$ ). Note that the scores have been rounded up. On a range of issues a total of about 67 per cent of students rated the Web site and conference as good to very good, i.e. the sum of Score 3 and Score 4.

\section{Score I Score 2 Score 3 Score 4

$\begin{array}{llll}5.7 & 27.4 & 43.4 & 23.2\end{array}$

Tabie 1: Student scores for all questions as a percentage of the total responses.

Questions 5 and 6 in the questionnaire related to the online debate:

5. The module conference was meant to give you an opportunity to get involved in a critical debate. To what extent did it succeed in this aim?

6. How useful did you find the ability to read the debates that took place in the threads for other groups?

Table 2 shows the total student responses to each of the above questions, by score and expressed as a percentage of the total number of responses to that question, i.e. sixty-one. The response to Question 5 shows that about 56 per cent of the students thought that the conference was 'good' or 'very good' at meeting its aim of giving the students exposure to a critical debate. The response to Question 6 shows that about 69 per cent of the students thought that the ability to read other students' debates was a 'good' or 'very good' opportunity for students. The response to Question 6 is a positive indicator that students may in future welcome work in the area of vicarious learning.

\begin{tabular}{|lcccc|}
\hline & Score I & Score 2 & Score 3 & Score 4 \\
Question 5 & 6.6 & 37.7 & 39.3 & 16.4 \\
Question 6 & 1.6 & 29.5 & 42.6 & 26.2 \\
\hline
\end{tabular}

Table 2: Student scores for specific questions on critical debate (Q5) and vicarious learning (Q6).

However, the generally positive results must be seen in the context of additional comments made by students on the questionnaire. These comments highlighted the fact that a major problem faced by the students was the constant crashing of the network. This in turn frustrated students as they tried to use the conferencing facility. Furthermore, individual comments made by students were not always positive with respect to the module Web site and online debate.

\section{Key issues in the implementation of networked on-campus learning}

Reflection on the implementation and evaluation of these two studies led to the distillation of five key issues that seem markedly to influence the effective delivery of networked collaborative learning. Briefly, the five issues are:

- the task goal set by the tutor;

- managing the relationship between new and traditional pedagogical techniques, including the changing role of the tutor; 
- managing student motivation;

- the delivery infrastructure;

- evaluation and feedback.

A first important issue is the task goal set by the tutor. The learning targets may be extrinsic to the online discussion or embedded within it. In the first study the networked communication was used as a means to an end. The assessed learning targets were the outputs of the groups in terms of online reports or the multimedia artifacts created by the groups. The online communication supported students in their project planning, co-ordination and sharing of resources. Furthermore, online monitoring allowed the tutor to get a much clearer insight into the ongoing project development processes within each group. This gave the tutor the confidence to make the assessment truly group-based. The use of networked communication thus enabled the tutor more effectively to realize 'traditional' goals for this module.

In the second study the tutor wanted to introduce a new emphasis on 'problem seeking' (Cook, 2000). The aim was to engage students in forming the problems they would tackle as well as proposing tentative solutions. This required a strong emphasis on discursive argumentative skills. The learning targets were thus intrinsic to the online discussion. Tutors may wish to introduce networked collaborative learning for a variety of purposes. The role of the students, the tutor and the appropriate means of assessing effectiveness are all affected by this primary choice.

The second issue with introducing networked communication concerns managing the relationship between traditional and new pedagogical techniques, including the activities of the tutor. The first study used a mixture of traditional (e.g. textbook) and new resources in the learning environment. The detailed exposition of underlying theory and concepts was conveyed through the textbook. The Web site acted to complement the book by providing access to multimedia illustrations and interactive examples. This combined courseware was in turn embedded in a class organization that was augmented through the use of electronic communication. The tutor did not usually intervene in the project group discussions except to provide general information and reminders of deadlines.

In study 2 the tutors were much more actively involved in promoting the quality (and quantity) of the online discussions. The skills required to act as an active online tutor seem different from those required in face-to-face tutorials (see JISC/CALT, 2000, for detailed guidelines). Tutors need to have a clear picture of the skills required when responding to a large number of students in a time-constrained, assessed, online debate, and liaison with other tutors, when involved, also needs to be orchestrated.

The tutors in study 2 developed a tactic of 'targeting', where weak contributors were targeted with questions in order to help get their number of postings up to the required minimum. Online tutors need to be aware that it is advisable for tutors to mix their interaction style between targeting low contributors with short questions, and longer 'quality time' style interactions. In this study, one tutor concentrated on the short directive postings, while the other focused more on engaging in reflective dialogue.

A third issue is thus the management of motivation and assessment for a particular student population. Both studies used the assessment criteria to some degree to motivate students 
to contribute to the online discussion groups. In the first study a set of clear, staged delivery targets was set to support the emergence of group discipline. These deliverables were formally assessed. The knowledge that the tutor had access to all the online discussions also seemed to have a marked motivating effect. Within this structured framework the M.Sc. students established healthy online discussions. The deliberate fostering of group communication by the tutor was not an important consideration.

The second study also used assessment as a motivating factor. In this case, the assessment was used to enforce contributions to the group discussions. The students were required to make a minimum number of contributions, and marks were awarded explicitly for this participation. There are a number of differences between the two studies in the nature of the task and the students. However, it is clear that tutors need to be aware of the powerful motivating effect of extrinsic motivators (e.g. assessment structure) and use these appropriately.

A fourth issue is the importance of the delivery support environment. In the second case study it was found that Netscape Collabra did not assist the course tutors in tracking students who were not making contributions to the online debate. This was done 'manually' and then a list of the names of non-contributors was posted on the noticeboard. By the end of the ten-day period for the assignment in case study 2 , only six out of sixty-four students failed to make a contribution to the conference. However, this is labour-intensive. High-level Virtual Learning Environments (VLEs) like WebCT provide essential tools that automate the process of tracking students. These free the tutor from time-intensive administrative tracking and free time for more constructive use of the tutor's time.

The final issue is the careful evaluation of the effectiveness of the delivery of on-campus networked learning. This evaluation underpins proposals for improved redesign. The feedback from the first study could not be immediately used to improve networked communication on the module as the tutor moved institutions. This experience, however, helped influence some design choices in the second study despite its different focus.

In terms of the second case study, the evaluation indicates that the approach taken to the assignment on the module gave the students the opportunity to engage in serious critical debate. However, there is also room for enhancing the learning experience. A future aim for this module could be to make student dialogues reusable, as a new kind of learning resource. Unfortunately, student attitudes, as revealed by a questionnaire, do not give us any indication as to the quality of the debate that took place. The marks allocated, and feedback given, by the tutors for individual student contributions do give some measure of the 'quality' of the interactions. However, such feedback will not reveal potentially useful information on the patterns of exchange between tutors and students. Future work intends to address this issue by conducting dialogue analysis of the conference interactions using a technique described in Cook (1998).

\section{References}

Atkins, M. (1993), 'Evaluating interactive technologies for learning', Journal of Curriculum Studies, 25, 333-42.

Boyle, T. (1997), Design for Multimedia Learning, London: Prentice Hall. 
Boyle, T. (1999), 'Using the Web to enhance learning about multimedia design', Monitor, Journal of the CTI Centre for Computing, 11 (Winter 1999), 18-21.

Boyle, T. and Payne, L. (1999), 'The design and evaluation of Web based multimedia learning resources', Proceedings of the 7th Annual Conference on the Teaching of Computing, University of Ulster, August 1999.

Collis, B. (1997), 'Pedagogical re-engineering: a pedagogical approach to course enrichment and redesign with the WWW', Educational Technology Review, 8 (Autumn/Winter 1997).

Cook, J. (1998), 'Mentoring, metacognition and music: interaction analyses and implications for intelligent learning environments', International Journal of Artificial Intelligence in Education, 9, 45-87.

Cook, J. (2000), 'Cooperative problem-seeking dialogues in learning', ITS 2000 - Fifth International Conference on Intelligent Tutoring Systems, 19-23 June 2000, Montreal, Canada.

England, E. and Finney, A. (1999), Managing Multimedia: Project Management for Interactive Media, 2nd edn, Harlow: Addison-Wesley.

JISC/CALT (2000), 'Effective networked learning in higher education: notes and guidelines', available from http://csalt.lancs.ac.uk/jiscladvice.htm.

Lipman, M. (1991), Thinking in Education, New York: Cambridge University Press.

McKendree, J., Stenning, K., Mayes, T., Lee, J., and Cox, R. (1998), 'Why observing a dialogue may benefit learning', Journal of Computer Assisted Learning, 14 (2), 110-19. 